\title{
ANÁLISE DO DESEMPENHO COMPETITIVO DAS AGROINDÚSTRIAS DE POLPA DE FRUTAS DO ESTADO DO PARÁ ${ }^{1}$
}

\author{
Antônio Cordeiro de Santana ${ }^{2}$
}

Resumo - Este trabalho objetivou determinar e analisar os principais indicadores de desempenho competitivo das agroindústrias de polpa de frutas do arranjo produtivo local de frutas das mesorregiões metropolitana de Belém e nordeste paraense. O desempenho competitivo foi avaliado por meio de indicadores ex-ante e ex-post dos modelos de organização industrial. Os resultados mostraram que as empresas estão operando com objetivos múltiplos, e a maior parte delas está obtendo significantes indicadores de aumento na capacidade produtiva, margem de lucro, parcela de mercado e emprego. Por fim, conclui-se que as empresas do aglomerado de frutas são competitivas nos mercados local, nacional e internacional do mix de polpa, composto de frutas da Amazônia e de demais frutas tropicais.

Palavras-chave: Agroindústria, competitividade, frutas tropicais, Amazônia.

\section{Introdução}

O Brasil é o maior produtor mundial de suco de laranja e o terceiro maior produtor de frutas tropicais, visto que exportou apenas $2,2 \%$ da produção de frutas in natura, no valor de US\$ 335,3 milhões em 2003. Os pólos do vale do São Francisco, no nordeste, e do nordeste paraense, no norte, destacam-se na produção das principais frutas tropicais degustadas no mercado internacional. O primeiro é especializado na produção e exportação de frutas tropicais in natura, e o segundo inicia a exportação de polpa de frutas da Amazônia.

\footnotetext{
Recebido em 23/09/2004 Aceito em 28/10/2004

2 D.Sc. em Economia Rural, Professor Adjunto da UFRA e Coordenador de Programação e Avaliação da ADA. santana@nautilus.com.br.
} 
A produção de frutas no nordeste paraense é uma das mais dinâmicas quanto às possibilidades de desenvolvimento na forma de sistemas agroflorestais sustentáveis. Há um leque de 15 tipos de frutas tropicais (regionais e exóticas) que são produzidas e beneficiadas pelas agroindústrias locais e na Amazônia como um todo. As frutas exóticas, de expressão, são abacaxi, maracujá, laranja, acerola e graviola. As frutas da Amazônia têm sabor diferenciado por natureza; e as de maior destaque comercial são açaí, cupuaçu, bacuri, taperebá e camu-camu, e a maior parte da produção ainda é extrativa. A produção de frutas manejada ou cultivada em sistemas agroflorestais, assim como o processamento agroindustrial, é intensiva em mão-de-obra.

O cultivo e, ou, a extração dessas frutas é realizada por pequenos agricultores. A sazonalidade é bem definida, e o volume produzido é insuficiente para atender à demanda das agroindústrias mesmo na safra, da maioria das frutas. Este fato está levando os produtores a se organizarem em sindicatos e cooperativas para ampliar os cultivos racionais diversificados e fazer o manejo das áreas de grande densidade de fruteiras nativas, visando abastecer as agroindústrias em volume e fluxo regular. É, pois, uma atividade intensiva em mão-de-obra.

Em 2003, a cadeia produtiva de frutas na Amazônia empregou, direta e indiretamente, cerca de 123 mil pessoas. O PIB, neste mesmo ano, foi de R \$ 355,4 milhões. É uma cadeia de atividades intensivas em mão-deobra e forte geradora de renda, em fluxo regular. A produção é estruturada em pequenas unidades produtivas, geralmente na forma de sistemas agroflorestais.

As exportações são efetivadas na forma de mix de polpa de frutas e, em 2003, atingiram o valor de US\$ 7,31 milhões. No primeiro semestre de 2004, foi exportado o equivalente a US\$ 5,04 milhões. A evolução, em relação a igual período de 2003 , foi de $24,47 \%$. Apenas $7,5 \%$ da produção de polpa de frutas regional foi exportada para os Estados Unidos e para alguns países da União Européia e Ásia, principalmente. O mercado nacional absorveu $75,5 \%$ da produção de polpa e o mercado local, cerca de $17 \%$. 
Atualmente, a demanda de polpa de frutas regionais, além de superior, cresce mais rapidamente do que a oferta. Já existe uma base instalada da agroindústria, porém apenas algumas estão processando dois ou mais tipos de frutas. Diante da escassez de frutas fora da safra (para algumas dessas frutas, a oferta é pequena mesmo na safra), há necessidade de a agroindústria trabalhar com várias linhas de produtos para diminuir a capacidade ociosa ao longo do ano. Nessas condições, são necessários pelo menos 10 tipos de frutas para que as agroindústrias mantenham um fluxo de processamento contínuo ao longo do ano.

A indústria de polpa de frutas está organizada em micro e pequenas empresas, com apenas três empresas de tamanho médio e uma grande empresa. As médias empresas e algumas pequenas e microempresas estão trabalhando com um mix de 10 a 15 tipos de polpa de frutas congelada e, ou, pasteurizada. Pequeno número destas implantou as boas práticas e fabricação e está a caminho da certificação internacional, por meio da Análise dos Perigos e Pontos Críticos de Controle (APPCC). As microempresas, em geral, processam apenas um tipo de fruta, o que as obriga a fechar no período de entressafra.

A pesquisa da qual foi extraído este artigo estuda a dinâmica evolutiva do arranjo produtivo de frutas paraense e orienta o desenho dos mecanismos de apoio ao processo de reestruturação agroindustrial para atender às demandas do mix de polpa das frutas regionais pelos mercados nacional e internacional.

O objetivo deste trabalho foi determinar as estratégias de crescimento em curso e alguns indicadores de desempenho competitivo das agroindústrias de polpa de frutas do arranjo produtivo local das mesorregiões metropolitana de Belém e nordeste paraense.

O trabalho está organizado em três seções, além desta introdução. Na segunda estão a metodologia de pesquisa e a fundamentação teórica para análise do desempenho competitivo das agroindústrias de polpa de frutas; Na terceira os resultados e as respectivas análises de indicadores ex-ante e ex-poste do desempenho competitivo; e na quarta as conclusões do trabalho. 


\section{Metodologia}

\subsection{Fundamentação teórica}

O desempenho competitivo de empresas do arranjo produtivo local ou agricluster de frutas do estado do Pará pode ser resultante da confluência de um conjunto de forças que manifestam seus efeitos no presente (por ocasião da formulação e implementação de estratégias para criar vantagens competitivas sustentáveis contra as fraquezas internas e as ameaças exógenas) e no futuro, ao se materializar no curso da concorrência por meio da ampliação das vendas, do market-share e do lucro.

Esse conceito pode ser avaliado por indicadores de desempenho exante e ex-post (Possas, 1999), na ótica dos modelos estrutura-condutadesempenho (Bain, 1968), das cinco forças de Porter (1990) e da competitividade sistêmica (Esser et al., 1999; Santana, 2003), inclusos nas análises de organização industrial. Os indicadores ex-ante vinculam-se às estratégias formuladas para criar vantagens competitivas sustentáveis, visando obter acesso privilegiado a fornecedores de matériasprimas, qualificação e formação de mão-de-obra, diferenciação e diversificação de produtos, inovações tecnológicas, organização produtiva (processo e produto) etc. Por sua vez, os indicadores ex-post são fruto das estratégias estabelecidas no curto prazo e que se consolidam no médio e longo prazo. Refletem os resultados que se efetivaram pelas empresas, como taxa de aumento das vendas, parcela de mercado e lucro. Todavia, os lucros esperados servem de baliza para julgar as decisões empresariais e para o planejamento da empresa, no presente, e a visualização dos efeitos, no futuro.

Em primeiro lugar, investiga-se o propósito de crescimento da empresa, que é a raiz da analise da organização industrial. Muitos são os esforços teóricos centrados para entender os reais objetivos de crescimento das empresas. É um tema em ebulição, razão pela qual o martelo ainda não foi batido em torno de um resultado preciso e suficiente. No entanto, parece evidente que o lucro seja o indicador predominante que, embora 
por abordagens diferentes, norteia os objetivos de crescimento das empresas.

A análise do desempenho competitivo das agroindústrias de polpa de frutas das mesorregiões metropolitana de Belém e nordeste paraense inicia-se com uma abordagem direta ao processo de obtenção de lucro. $\mathrm{Na}$ verdade, para obter lucro, que é uma medida universal do desempenho empresarial, as empresas indicaram vários caminhos, inclusive o de não pensar em longo prazo, preferindo não se manifestar a respeito do assunto.

A estratégia principal das agroindústrias de polpa de frutas é a diversificação horizontal ${ }^{3}$ dos produtos. Esta estratégia incorpora várias posições teóricas, desde a marginalista (Marshall, 1982), passando pelos institucionalistas (Williamsom, 1985 e 1999) até a evolucionista (Schumpeter, 1976; Nelson; Winter, 1973 e 2002).

A abordagem marginalista ancora sua orientação analítica nas unidades que se destinam à maximização de lucros e à alocação racional dos recursos e formação de preço, no âmbito interno das empresas. Tudo se fundamenta na lei dos rendimentos decrescentes, em que o tamanho ótimo da empresa se orienta para o custo médio mínimo em longo prazo. Os institucionalistas comportamentais pautam no conhecimento real de que riscos, incertezas e informações assimétricas, conjuminados com o comportamento oportunista dos agentes, levam a uma condição subótima do lucro. Em razão disso, tenta-se otimizar uma função de utilidade gerencial, sujeita a um conjunto de restrições como estratégias de diversificação da produção, capacidade de gestão dos tomadores de decisão e distribuição dos lucros retidos na empresa, além das formas de organização interna dos processos de produção em departamentos, células de produção, rodízio e polivalência no trabalho, sistema just-intime, círculo de controle de atividade.

\footnotetext{
${ }^{3}$ Diversificação é um processo que envolve a venda de produtos de uma linha de produtos já conhecida e fabricada com a mesma tecnologia em uma nova área de comercialização; a venda de novos produtos em áreas antigas de comercialização, fabricados com nova tecnologia; ou a venda de novos produtos em novas áreas de comercialização e fabricados com tecnologia nova. Esse processo, portanto, pode fazer parte de longo período de produção da empresa.
} 
Já os evolucionistas neo-shumpterianos orientam seus argumentos para o processo de incorporação de inovações tecnológicas ao produto, processo produtivo e gestão empresarial, como elementos capazes de mover a diferenciação de produtos e orientar o esforço de venda, de modo a resultar em maior parcela de mercado.

Dada a capacidade limitada do consumidor em comparar qualidade, pelas preferências irracionais, a diferenciação de produto via inovação tecnológica que atua na natureza, embalagem, design, estilo e qualidade, em conjunto com a associação entre diversificação de produto e esforço de venda, permite aos empresários alcançar o objetivo de aumentar a produção e a rentabilidade em curto prazo, ajustar o tamanho da empresa e reduzir preço, no longo prazo.

A diversificação pode ser vista como a expansão da empresa para novos mercados fora de sua área original ou local de atuação. Esta é uma alternativa de grande relevo para viabilizar o crescimento da empresa, dado que permite superar os limites dos mercados em que concorre, mediante a gestão de diversas atividades, e dinamizar as forças que influenciam o crescimento empresarial (Britto, 2002). Em termos gerais, há várias razões pelas quais as empresas tipicamente combinam os objetivos de crescimento e diversificação. O crescimento por meio da diversificação oferece à empresa uma posição de mercado mais forte e segura, em comparação à de seus competidores, fornecedores e clientes. $\mathrm{O}$ crescimento pela diversificação de uma gama de produtos libera a empresa da expressiva dependência de um ou de poucos produtos e ajuda na proteção contra o surgimento de novos e melhores produtos. Enfim, o crescimento por meio da diversificação fornece os meios para buscar os demais objetivos da empresa, como a obtenção de lucros mais altos e a expansão das vendas.

Nas agroindústrias de polpa de frutas especificamente, a diversificação de produtos otimiza a utilização de matéria-prima, a ocupação dos recursos humanos e, principalmente, as unidades processadoras, que são pontos fundamentais para redução dos custos de produção (gerando econo- 
mias de escala e de escopo), princípio que está na base da teoria marshalliana da maximização do lucro. Simultaneamente, a diversificação da produção permite ajustar melhor a produção aos gostos e preferências dos consumidores, contribuindo para reduzir o risco de preço e adequar o esforço de venda, otimizando as ações administrativas dos empresários que combinam a divisão interna de trabalho com a utilização das máquinas, de acordo com a tecnologia empregada (dando ensejo ao movimento de criação de algo novo em substituição ao velho), e ampliar o volume das vendas. Este princípio, pelo que se observa, tira o foco da maximização do lucro e centra-se na maximização de receitas, por meio das vendas, sujeitas a um nível aceitável de lucro, e da capacidade administrativa ou gerencial do empresário, que é o fundamento da teoria comportamental e, ou, institucionalista, ou genericamente a nova Teoria da Organização Industrial (Barney, 1997; Cabral, 2000; Kon, 1999; Kupfer; Hasenclevel, 2002; Tirole, 2001).

A teoria comportamental é particularmente a teoria da racionalidade limitada, uma vez que a gerência se contenta com soluções e cursos de ação satisfatórios ou desejáveis, em vez de adotar estratégias mais difíceis de procurar, a cada momento, a melhor alternativa possível. A estratégia de crescimento por meio da diversificação é incluída no leque das estratégias satisfatórias, pelas razões apresentadas no início dessa discussão. Por fim, a diversificação possibilita à empresa sair do status quo do mundo dos negócios, que é ficar preso a um produto, e ganhar uma posição mais forte no mercado, para negociar com clientes e fornecedores em condições favorecidas, ao permitir negociar contrato em bases sustentáveis, o que contribui para equacionar o problema de mensuração reconhecido pela teoria institucionalista, que nasce das dificuldades postas pela racionalidade limitada e pelo oportunismo dos agentes. No caso das frutas, é condição necessária e, no curto prazo, suficiente para a sobrevivência das empresas, uma vez que não há plantios racionais apoiados em tecnologia de irrigação e reprodução para programar o fluxo de produção. 
As empresas também estão evoluindo para a integração horizontal, como estratégias competitivas ao modo da teoria institucionalista. A integração se dá pela formação de alianças ou parcerias firmadas com as empresas fornecedoras de matéria-prima (no caso, os produtores familiares, produtores cooperados e, ou, intermediários) e com outras empresas de menor tamanho, para produzir uma linha de polpa de frutas de sua empresa por meio de subcontratação (mesmo que de forma descontínua), formando um encadeamento para trás (backward effects) e fortalecendo os meios de assegurar matéria-prima com regularidade na safra, qualidade e menor custo de transação, bem como diversificar a produção e aumentar o volume de produto para atender à demanda. Compreende também as vinculações para frente, fruto das alianças firmadas com clientes (supermercados, distribuidoras, empresas de sorvete, intermediários), gerando os encadeamentos para frente (forward effects) na cadeia de produção-distribuição-consumo.

\subsection{Procedimento analitico}

Dadas as condições de infra-estrutura e proximidade da matéria-prima e dos mercados consumidores, a quase totalidade das agroindústrias está implantada nas mesorregiões metropolitana de Belém e nordeste paraense, que constituem a área de estudo.

As agroindústrias ou empresas entrevistadas foram eleitas com base nos cadastros do Serviço Brasileiro de Apoio às Micro e Pequenas Empresas (Sebrae) e da Delegacia Federal de Agricultura (DFA). Foram consideradas apenas as empresas formais, cujos produtos estão registrados no Ministério da Agricultura. Com base nesse critério, foram identificados os 10 municípios onde essas empresas estão sediadas, para efetivação da pesquisa.

A amostra foi definida de forma intencional, após identificação do conjunto de empresas julgadas com potencial para aplicar os questionários. Muitas empresas, embora apresentasse o registro de algum produto, ain- 
da não estavam efetivamente operando ou já tinham fechado suas portas. Após esse primeiro filtro, optou-se por incluir todas as empresas multiproduto na amostra. No que concerne às empresas uniproduto, $\mathrm{o}$ universo foi reduzido àquelas com possibilidade mínima de fornecer informações para preencher a maioria das perguntas incluídas no questionário. Todas as que se enquadraram nesse critério foram incluídas no universo da pesquisa, porém algumas não se dispuseram a preencher o questionário, sobretudo a maior empresa do estado do Pará, especializada na produção de polpa de maracujá.

No município de Belém, foi contemplado um conjunto de agroindústrias representativo das micro e pequenas empresas e, nos demais, todas as empresas em operação. O total de empresas entrevistadas soma 27, das quais 17 estão sediadas na mesorregião metropolitana de Belém e as 10 restantes, nos municípios da mesorregião nordeste paraense. Quanto à diversificação da produção, 19 são uniproduto, pois realizam o processamento de apenas um tipo de fruta, e 18 processam açaí e uma, acerola. As oito restantes são multiproduto e beneficiam três a 15 tipos de frutas diferentes (açaí, acerola, abacaxi, bacuri, caju, camu-camu, carambola, cupuaçu, goiaba, graviola, laranja, mangostão, maracujá, murici e taperebá).

O instrumento de coleta dos dados foi um questionário preparado para abranger todos os elementos de fundamento da análise de arranjos produtivos locais e competitividade sistêmica. Neste artigo, foi explorado apenas um bloco de questões orientadas para avaliar o desempenho competitivo das agroindústrias de polpa de frutas. O processamento dos dados, na forma de tabelas de freqüências, assim como a construção de alguns índices, foi realizado no Software SPSS.

O escopo da análise é descritivo e interpretativo, combinado com a construção de indicadores econômicos e índices qualitativos para fundamentar as evidências dos resultados com os postulados teóricos. 


\section{Resultados e discussão}

\subsection{Objetivos de crescimento das agroindústrias}

Os objetivos de crescimento das agroindústrias de polpa de frutas foram delineados claramente com as respostas dadas à seguinte pergunta: Quais são os principais objetivos de sua empresa? As respostas foram reunidas na Tabela 1.

A consolidação desses objetivos materializa-se nas medidas de desempenho. Pelo que se observa, o objetivo de crescimento dominante entre os empresários de polpa de frutas, que representam $85,2 \%$ do total, é aumentar o volume de vendas, $37 \%$ de microempresas, $44,5 \%$ de pequenas empresas e 3,7\% de médias empresas (Tabela 1). Este é o objetivo central das empresas que exploram os limites do planejamento administrativo da empresa, na suposição de que o prestígio dos administradores (e da empresa) se associe ao volume de vendas, que, por sua vez, está diretamente ligado ao market-share da empresa. Essa estratégia tem raiz no sucesso de longo prazo, pois, estrategicamente, pode ser mais sustentável para a empresa fixar preços baixos, com vistas em competir efetivamente por maior parcela de mercado. Essa atitude, todavia, depende diretamente do tamanho da empresa e do grau de integração vertical ou horizontal. Obviamente que expressiva participação no mercado, por meio do aumento das vendas, é um valioso ativo, visto que reflete a capacidade da empresa de competir eficientemente e de beneficiar-se das economias de escala e do reconhecimento de ser uma empresa líder. Atualmente, apenas uma empresa domina 26,02\% das vendas de polpa de frutas. 
Tabela 1 - Objetivos de crescimento das agroindústrias de polpa de frutas do estado do Pará, 2004

\begin{tabular}{lcccc}
\hline Porte & $\begin{array}{c}\text { Aumentar o } \\
\text { volume de vendas }\end{array}$ & $\begin{array}{c}\text { Aumentar o tamanho } \\
\text { da empresa }\end{array}$ & $\begin{array}{c}\text { Maximizar o } \\
\text { lucro }\end{array}$ & $\begin{array}{c}\text { Outro } \\
\text { objetivo }\end{array}$ \\
\hline Micro & $37.0 \%$ & $22.2 \%$ & $14.8 \%$ & $3.7 \%$ \\
Pequena & $44.5 \%$ & $33.4 \%$ & $33.4 \%$ & $3.7 \%$ \\
Média & $3.7 \%$ & - & $3.7 \%$ & $3.7 \%$ \\
Total & $\mathbf{8 5 . 2 \%}$ & $\mathbf{5 5 . 6 \%}$ & $\mathbf{5 1 . 9 \%}$ & $\mathbf{1 1 . 1 \%}$ \\
\hline Número de empresa & 23 & 15 & 14 & 3 \\
\hline
\end{tabular}

Fonte: Pesquisa de campo.

Em seguida, aparecem 55,6\% das empresas que pensam em crescer mediante aumento no tamanho físico da planta industrial, sendo $22,2 \%$ microempresas e 33,4\% pequenas empresas. As médias empresas, por apresentarem tamanho ajustado à oferta de matéria-prima regional e à evolução da demanda nos mercados local e nacional, não se incluem neste objetivo. O objetivo desses empresários é criar condições para obter empréstimo junto à rede bancária e acumular capital para facilitar as negociações diferenciadas junto aos fornecedores de matéria-prima e aos clientes. Na base desse pensamento está a idéia de se transformar em empresa líder e dominar o mercado de polpa de frutas, fazendo uma integração horizontal por meio da subcontratação de microempresas para realizar a produção linhas de polpa de frutas específicas a dado nicho de mercado.

Para esses empresários, está claro que, sem ampliar o tamanho da empresa, torna-se difícil criar as economias de escala, de escopo e de aglomeração, mediante produção diversificada, incremento na diferenciação do produto e integração com clientes e fornecedores. Em suma, para fazer uso contínuo de inovações tecnológicas para diferenciar produto, aumentar a produtividade do trabalho e do capital e produzir na quantidade exigida pelo mercado local, nacional e internacional, segundo a segmentação e exigência dos consumidores em qualidade e preço, há necessidade de uma planta de maior tamanho e ampliação da rede de empresas. 
Por último, 51,9\% das agroindústrias afirmaram que o objetivo tácito de crescimento é maximizar o lucro, ou seja, agem sob os ditames da teoria marginalista. Destas, 14,8\% são microempresas; 33,4\%, pequenas empresas; e 3,7\%, médias empresas. Nesse caso, o esforço é centrado na alocação e na remuneração dos fatores de produção capital e mão-deobra e nos insumos fornecidos. O espírito é tornar o processo produtivo eficiente para produzir com custo mínimo e adicionar margem de lucro para formar o preço de venda.

Em virtude da orientação para obter lucro em uma economia de empresas concorrenciais, como é o caso das agroindústrias de polpa de frutas, normalmente é aceitável, como verdade, que as empresas fazem todo o esforço possível para maximizar seus lucros. Entretanto, é oportuno ter claro que o objetivo é o lucro máximo e que as empresas irão se comportar como se fossem maximizadoras de lucro, dado que o lucro máximo é de difícil constatação.

A estratégia de venda adotada pelas empresas de polpa de frutas nas mesorregiões metropolitana de Belém e nordeste paraense segue dois padrões distintos. No primeiro, a venda é realizada mediante contato direto com o cliente, que pode ser supermercado, distribuidora, trader ou intermediários agentes da comercialização. No segundo caso, a empresa vende por meio de gôndola alugada em supermercado, abastecida pela própria empresa, e, ou, por meio de loja de polpa de frutas própria. Os $11,1 \%$ restantes, atribuídos ao conjunto de outros objetivos da empresa, derivam de uma forma ou de outra desses três primeiros.

O que se visualizou nas respostas dadas a essa questão, em torno das estratégias e dos objetivos de crescimento das empresas de polpa de frutas, está vinculado ao conjunto de indicadores ex-ante do desempenho competitivo das empresas. Os resultados ex-post, que afloram dos indicadores de desempenho competitivo, se devem ao sucesso na implementação e na consolidação desses objetivos, o que depende signi- 
ficativamente das ações administrativas dos gerentes ou empresários. No caso específico das empresas de polpa de frutas, os próprios empresários respondem pela função de planejamento administrativo dos negócios.

\subsection{Medidas de desempenho competitivo}

\subsubsection{Capacidade produtiva}

Uma primeira medida de desempenho ex-post está ligada à observação sobre quanto cada empresa cresceu em relação ao ano anterior. Esta medida indica o sucesso ou o fracasso das estratégias e objetivos traçados no ano anterior. Pelo que se observa a partir dos resultados mostrados na Tabela 2, das oito empresas que mantiveram a mesma capacidade produtiva (29,63\% do total de empresas pesquisadas), quatro são microempresas; três, pequenas empresas; e uma, empresa de tamanho médio. Apenas uma empresa encolheu, perdendo competitividade.

Tabela 2 - Variação na capacidade de processamento de polpa de frutas das empresas, entre 2002 e 2003

\begin{tabular}{lccccc}
\hline Categoria & A mesma & $\mathbf{1 0 - 1 5 \%}$ & $\mathbf{1 5 - 1 0 0 \%}$ & $\mathbf{> 1 0 0 \%}$ & Diminuiu \\
\hline Micro & $50.0 \%$ & $25.0 \%$ & $45.5 \%$ & $33.3 \%$ & - \\
Pequena & $37.5 \%$ & $75.0 \%$ & $45.5 \%$ & $66.7 \%$ & $100.0 \%$ \\
Média & $12.5 \%$ & - & $9.1 \%$ & - & - \\
Total & $\mathbf{1 0 0 . 0 \%}$ & $\mathbf{1 0 0 . 0 \%}$ & $\mathbf{1 0 0 . 0 \%}$ & $\mathbf{1 0 0 . 0 \%}$ & $\mathbf{1 0 0 . 0 \%}$ \\
\hline Número de empresas & 8 & 4 & 11 & 3 & 1 \\
\hline
\end{tabular}

Fonte: Pesquisa de campo.

Por outro lado, 18 empresas, cerca de 66,67\%, ampliaram a capacidade produtiva em relação ao ano anterior. Este é um forte indicativo de que as estratégias formuladas e implementadas foram capazes de ampliar, simultaneamente, o volume de vendas e a parcela de mercado. O sucesso destas empresas veio por meio da diversificação e diferenciação de produtos, treinamento da mão-de-obra, maior capacitação gerencial, for- 
mação de alianças com fornecedores e clientes, participação em feiras, investimento em tecnologias e qualidade dos produtos, e observação das tendências do mercado de polpa de frutas, que, na visão de muitos empresários, é amplo, porém os segmentos são pouco conhecidos.

Com relação à magnitude da variação no crescimento da capacidade produtiva das empresas de polpa de frutas, os resultados mostram que $22,22 \%$ do total das empresas que ampliaram a capacidade produtiva cresceu $10 \%$ a $15 \% ; 61,11 \%, 15$ a $100 \%$; e $16,67 \%$ mais que dobraram suas capacidades produtivas (Tabela 2).

Das empresas que ampliaram a capacidade produtiva acima de 100\%, cerca de $33,3 \%$ e $66,7 \%$ são, respectivamente, micro e pequenas empresas. Entre as 11 empresas que aumentaram a capacidade produtiva entre $15 \%$ e $100 \%$, as micro e pequenas empresas representam, respectivamente, 45,5\% cada, e as médias, 9,1\%. Já as empresas que incrementaram suas capacidades produtivas entre $10 \%$ e $15 \%$, cerca de $25 \%$ é de microempresas e $75 \%$, de pequenas empresas. No curto prazo, esse desempenho é considerado mais que satisfatório e, se perdurar no longo prazo, ultrapassa as expectativas normais de sucesso empresarial, diante do quadro recessivo por que passa a economia. Essas empresas, cuja base de estratégias está na implementação de inovações tecnológicas e de gestão e no investimento em capital humano, representam os pontos de convergências dos postulados teóricos que tentam entender e justificar o sucesso de um conjunto de empresas que se movem (obtendo sucesso) na contramão do status quo adotado pelas empresas que mantiveram ou diminuíram suas capacidades produtivas. Este, sem dúvida, é um caso que perfeitamente se enquadra no processo schumpeteriano da destruição criadora. 


\subsubsection{Capacidade ociosa}

Outro indicador importante de desempenho competitivo que se situa entre o curto e o longo prazo é a capacidade ociosa, portanto, pode ser avaliado, a princípio, tanto como indicador ex-ante quanto ex-post de desempenho das empresas, por suas implicações na empresa (Tabela $3)$.

Pelos resultados apresentados na Tabela 3, observa-se que 7,4\% das empresas pesquisadas trabalhavam com capacidade ociosa entre 11$20 \%$, ou seja, em plena capacidade de funcionamento, se considerado o nível médio de funcionamento pleno da indústria brasileira, que operou abaixo do índice de $80 \%$, de acordo com o indicador de utilização da capacidade instalada da sondagem industrial de Conjuntura Econômica (ago. 2003). Neste grupo, apenas as microempresas e as pequenas empresas estão enquadradas. Outro grupo de empresas, cujas estratégias foram menos arrojadas, cerca de $3,7 \%$ do total, estava operando com capacidade ociosa que variava de $21 \%$ a $35 \%$.

Tabela 3 - Nível de capacidade ociosa das agroindústrias de polpa de frutas do estado do Pará, 2004

\begin{tabular}{lcccc}
\hline Categoria & $\mathbf{1 1 - 2 0} \%$ & $\mathbf{2 1 - 3 5 \%}$ & $\mathbf{3 6 - 5 0 \%}$ & $\mathbf{> 5 0 \%}$ \\
\hline Micro & 3,7 & - & 14,8 & 18,5 \\
Pequena & 3,7 & 3,7 & 18,5 & 29,9 \\
Média & - & - & 7,4 & - \\
Total & 7,4 & 3,7 & 40,7 & 44,4 \\
\hline Número de empresas & $\mathbf{2}$ & $\mathbf{1}$ & $\mathbf{1 1}$ & $\mathbf{1 2}$ \\
\hline
\end{tabular}

Fonte: Pesquisa de campo. Uma empresa não respondeu a esta pergunta.

$\mathrm{Na}$ faixa de $36 \%$ a $50 \%$, encontra-se cerca de $40,7 \%$ das empresas, sendo $14,8 \%$ de microempresas; $18,5 \%$, pequenas empresas; e 7,4\%, médias empresas. Entre estas empresas, certamente, está uma parte daquelas que obtiveram desempenho negativo ou estático, em termos de variação da capacidade produtiva. 
Por último, tem-se que $44,4 \%$ das empresas pesquisadas continuam operando com mais de 50\% da capacidade instalada ociosa. Todas estas, certamente, estão enquadradas nas que encolheram de tamanho produtivo em relação ao ano anterior, visto que não estão cobrindo os custos fixos e, talvez, também não estejam cobrindo os custos operacionais.

Os fatores arrolados para operar com capacidade ociosa foram escassez de matéria-prima e sazonalidade $(92,6 \%)$; falta de capital de giro $(33,3 \%)$; capacidade de armazenamento $(14,8 \%)$; custo de produção $(14,8 \%)$; empresas informais $(11,1 \%)$. Todos os fatores estão inter-relacionados com o desempenho competitivo das empresas. A falta de capital de giro manifesta-se na impossibilidade de ampliar o tamanho da empresa e as condições de processar e armazenar o produto.

A escassez de matéria-prima está intimamente ligada à sazonalidade da produção e constitui fator de maior limitação ao desempenho das agroindústrias, sobretudo as uniproduto, uma vez que a maior parte da produção é oriunda do extrativismo, de modo que só há disponibilidade do produto na ocasião das safras. O processo de domesticação de várias espécies de frutas, como bacuri, taperebá, e a expansão dos plantios de cupuaçu, açaí e demais frutas não acompanham o ritmo de evolução da demanda. Para minimizar o efeito sazonal, a empresa precisa de capital de giro para tornar a planta industrial multiproduto, combinando o processamento de 13 ou mais frutas ao longo do ano, para otimizar o uso da capacidade instalada. Nas condições atuais de oferta, as empresas necessitariam processar cerca de 13 tipos de frutas diferentes para assegurar o funcionamento da empresa ao longo do ano, com fluxo regular de produção para o mix de polpa de frutas. Por isso, o maior nível de capacidade ociosa está nas pequenas e microempresas especializadas no processamento de apenas um tipo de fruta.

A escassez de produto e a capacidade de armazenamento também se complementam para determinar a capacidade ociosa. Se a produção, além de sazonal, é extrativa, a oferta concentra-se em curto espaço de tempo. Para tirar proveito, as empresas precisam operar no máximo de suas capacidades de processamento, mas, para isso, necessitam arma- 
zenar o produto, dado que as vendas não fluem com igual rapidez e, como não dispõem de capital de giro, passam a operar o restante do tempo com capacidade ociosa, dado que a maioria das plantas é uniproduto, especializadas apenas no processamento do açaí. Esse foi o fator apontado como o principal gargalo que limita a expansão das empresas.

Aliados a esses fatores, o custo de transporte, as perdas no curso do canal de comercialização das frutas até a agroindústria, a mão-de-obra e, principalmente, a energia elétrica limitam a operacionalidade das empresas em plena capacidade. Em razão disso, na época da safra muitas microempresas entram no mercado, o que compromete as estratégias de venda das empresas já estabelecidas no arranjo, por aumentar a concorrência.

Por outro lado, a capacidade ociosa, quando utilizada estrategicamente, pode funcionar como forte barreira à entrada de novas empresas na indústria, no período da safra, dado que, para qualquer variação positiva de ampliação das oportunidades de mercado, basta que as empresas ampliem seus níveis de produção via recontratação de funcionários dispensados ou passem a operar com um terceiro turno e utilização da plena capacidade operacional das máquinas e equipamentos já adquiridos e prontos para funcionar. Portanto, a manutenção de adequado nível de capacidade ociosa pode funcionar como elemento estratégico para manutenção e, ou, ampliação do market-share em curto prazo, ou seja, no período de safra das frutas regionais. Entretanto, grande capacidade ociosa pode sinalizar fraqueza da empresa por inadequação da planta ou ineficiência administrativa, dado que pode caracterizar incapacidade de remuneração do capital fixo, abrindo espaço para a entrada de novas empresas na indústria.

Outro grupo de empresas, que corresponde a 18,5\% do universo pesquisado, indicou o baixo poder aquisitivo da população regional, em conseqüência da recessão que atravessa a economia brasileira e da concorrência de produtos de inferior qualidade, o que força a diminuição da atividade produtiva. 
Até o momento, analisou-se a influência combinada dos fatores ex-ante com os ex-post. Deste ponto em diante, a análise direciona-se para os indicadores ex-post: margem de lucro, custo de produção, variação no emprego e market share.

Quanto à margem de lucro, tem-se que 22,3\% das empresas estão no vermelho ou apenas empatando e 77,7\% operam com lucro. Destas, $33,3 \%$ obtiveram lucro inferior a 10\% em relação aos custos totais, $29,6 \%$, margem de lucro de $10 \%$ a $20 \%$; e $14,8 \%$, margem de lucro superior a $20 \%$ (Tabela, 4).

As médias empresas operam com margem de lucro até 10\%. A maioria das agroindústrias, cerca de 44,4\% das que operam com lucro, obtém margem de lucro acima de $10 \%$. Este indicador mostra que sobretudo as $25,9 \%$ agroindústrias que estão obtendo lucro acima de $15 \%$, por ser uma taxa de lucro, em curto prazo, acima da média $(13,2 \%)^{4}$, podem estimular a entrada de novas empresas na indústria de polpa de frutas nos arranjos produtivos das mesorregiões metropolitanas de Belém e nordeste paraense, dado que o mercado opera em concorrência pura e não há barreiras à entrada.

${ }^{4}$ Média obtida a partir dos pontos médios dos intervalos das classes de variação da margem de lucro. 
Tabela 4 - Margem de lucro das agroindústrias de polpa de frutas do estado do Pará, 2004

\begin{tabular}{lccccc}
\hline \multirow{2}{*}{ Categoria } & \multicolumn{5}{c}{ Margem de lucro sobre o custo total } \\
\cline { 2 - 6 } & $\mathbf{0 - 5 \%}$ & $\mathbf{5 - 1 0 \%}$ & $\mathbf{1 0 - 1 5 \%}$ & $\mathbf{1 5 - 2 0 \%}$ & Mais de 20\% \\
\hline Micro & - & 7.4 & 7.4 & - & 7.4 \\
Pequena & - & 18.5 & 11.1 & 11.0 & 7.4 \\
Média & 3.7 & 3.7 & - & - & - \\
Total & $\mathbf{3 . 7}$ & $\mathbf{2 9 . 6}$ & $\mathbf{1 8 . 5}$ & $\mathbf{1 1 . 1}$ & $\mathbf{1 4 . 8}$ \\
\hline Número de empresas & 1 & 8 & 5 & 3 & 4 \\
\hline
\end{tabular}

Fonte: Pesquisa de campo. Seis empresas não responderam a esta pergunta.

O ponto que norteia a decisão de entrada de novas empresas na indústria é a taxa de variação positiva do lucro, por sinalizar uma perspectiva de permanência em uma trajetória de médio e, ou, longo prazo. Nesse aspecto, as empresas da indústria de polpa de frutas estabeleceram estratégias de crescimento para ajustar a escala de produção e ampliar a margem de lucro, o que pode ser aferido por meio dos resultados da Tabela 5 .

Assim, tem-se que $75 \%$ e $25 \%$, respectivamente, das microempresas e das empresas de pequeno porte mantiveram, em 2003, as mesmas margens de lucro que obtiveram em 2002. Em perspectiva, 25\%, 58,3\% e $16,7 \%$ das micro, pequenas e médias empresas, respectivamente, conseguiram ampliar suas margens de lucro em relação a 2002. Por outro lado, $33,2 \%$ e $66,7 \%$ das micro e pequenas empresas amargaram redução da taxa de lucro em relação ao período anterior, ou seja, perderam competitividade, visto que não obtiveram ganho de mercado por meio do esforço de venda.

As agroindústrias que conseguiram incrementar as margens de lucro o fizeram às custas do esforço de avançar na diferenciação de produto, treinamento de mão-de-obra e ajustamento na organização interna da empresa, com vistas em aumentar as vendas e conquistar maior parcela de mercado. 
Tabela 5 - Evolução da margem de lucro das agroindústrias de polpa de frutas do estado do Pará, 2002 a 2003).

\begin{tabular}{lcccc}
\hline Categoria & Diminuiu & Permaneceu & Aumentou & Não sabe \\
\hline Micro & $33.3 \%$ & $75.0 \%$ & $25.0 \%$ & - \\
Pequena & $66.7 \%$ & $25.0 \%$ & $58.3 \%$ & $100.0 \%$ \\
Média & - & - & $16.7 \%$ & - \\
Total & $\mathbf{1 0 0 . 0 \%}$ & $\mathbf{1 0 0 . 0 \%}$ & $\mathbf{1 0 0 . 0 \%}$ & $\mathbf{1 0 0 . 0 \%}$ \\
\hline Número de empresas & 6 & 8 & 12 & 1 \\
\hline
\end{tabular}

Fonte: Pesquisa de campo.

A rentabilidade apropriada para o estudo dos efeitos do poder de mercado das empresas, de acordo com a teoria do preço, é dada pela razão [(preço - custo marginal)/preço]. Como essa medida ideal não é observável diretamente, adotou-se uma medida alternativa com base nos dados da pesquisa de campo, que é dada pela razão [(preço - custo variável médio)/preço], uma aproximação adequada do excesso de vendas sobre os custos em relação ao total de vendas, ou da taxa de lucro sobre as vendas. Os resultados obtidos são apresentados na Figura 1.

Pelo que se observa, apenas três empresas, duas microempresas (9 e 16) e uma pequena empresa (12), apresentaram rentabilidade negativa e todas são uniproduto, especializadas no processamento de açaí. As demais apresentaram rentabilidade positiva e alta. A rentabilidade média foi de $47,16 \%$; e não obstante ser uma taxa elevada, 18 empresas ou $66,67 \%$ do universo pesquisado apresentaram rentabilidade superior à média. Nesse patamar está uma empresa de tamanho médio (50\%), seis das 11 pequenas empresas (54,55\%) e 11 das 14 microempresas (78,57\%). As duas maiores são de empresas multiprodutos (números 27 e 15).

Esse indicador de rentabilidade de curto prazo sinaliza um rápido processo de mudança na estrutura do mercado, com a entrada de empresas de tamanho médio, uma vez que as barreiras são frágeis para este porte de 
empresa. Isto pode mudar a configuração do mercado de baixa concentração para de elevada concentração, sobretudo se for tomada como indicador de tamanho a disponibilidade de oferta de açaí, por ser a fruta de maior área colhida. Para que isto não ocorra de forma desordenada, é preciso apoiar a ampliação da capacidade de processamento das microempresas e das empresas de pequeno porte, na direção de plantas multiproduto e com boa capacidade de armazenamento. $\mathrm{O}$ tamanho adequado é indicado mais adiante.

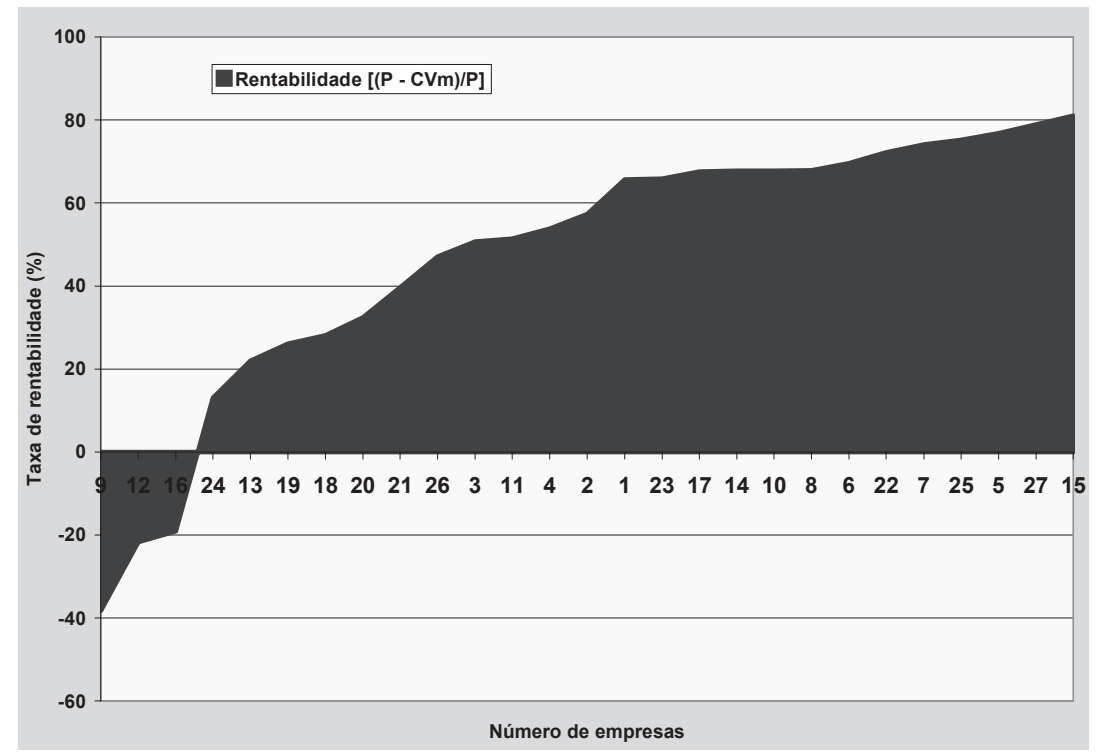

Figura 1 - Rentabilidade das empresas processadoras de frutas nas mesorregiões metropolitanas de Belém e nordeste paraense, 2004. 


\subsubsection{Parcela de mercado ou market-share}

O clássico indicador de desempenho ex-post é o que se refere ao marketshare da empresa ou a parcela do mercado que a empresa domina. No caso dos resultados que são mostrados na Tabela 6 , computou-se apenas o movimento desta parcela de mercado. Observa-se que as micro e pequenas empresas tiveram suas parcelas de mercado diminuídas em $33,3 \%$ e $66,7 \%$, respectivamente. Cerca de $83,3 \%$ e $16,7 \%$ destas mesmas classes de empresas conseguiram manter suas parcelas de mercado. Por outro lado, cerca de $27,8 \%, 61,1 \%$ e $11,1 \%$ das empresas de porte micro, pequeno e médio ampliaram suas participações no mercado. Os dois fatores principais que contribuíram para isto foram a falta de capital de giro e o custo da matéria-prima, aliados à perda de poder aquisitivo da população. Cabe ressaltar, entretanto, que o principal fator que limita o crescimento da empresa e a ampliação do market share é a capacidade de armazenamento por meio de câmeras frigoríficas. Uma câmera frigorífica com capacidade para armazenar três mil toneladas custa em torno de R $\$ 1,50$ milhão, o que se torna forte barreira ao desempenho das empresas. 
Tabela 6 - Evolução da parcela de mercado das agroindústrias de polpa de frutas do estado do Pará, 2004

\begin{tabular}{lccc}
\hline Porte & Diminuiu & Permaneceu & Aumentou \\
\hline Micro & $33.3 \%$ & $83.3 \%$ & $27.8 \%$ \\
Pequena & $66.7 \%$ & $16.7 \%$ & $61.1 \%$ \\
Média & - & - & $11.1 \%$ \\
Total & $\mathbf{1 0 0 . 0 \%}$ & $\mathbf{1 0 0 . 0} \%$ & $\mathbf{1 0 0 . 0 \%}$ \\
\hline Número de empresas & 3 & 6 & 18 \\
\hline
\end{tabular}

Fonte: Pesquisa de campo.

Entre as empresas que ampliaram suas participações nos mercados de polpa de frutas, nota-se que esse porcentual está condizente com as que conseguiram manter e, ou, ampliar sua margem de lucro, o que indica que o ajuste implementado por tais empresas resultou em dupla vantagem: ampliação do mercado e aumento da margem de lucro, simultaneamente. Um dos pontos fortes que se vinculam a esse sucesso é a estratégia de integração com os fornecedores de matérias-primas e com as lojas de venda, além do esforço para diversificar e diferenciar produtos, agregando valor, adequando o estilo e incorporando utilidades de uso para os clientes, combinado com o esforço de venda.

Na Tabela 7 estão os resultados do indicador de desempenho competitivo do emprego. Das pequenas e médias empresas, $66,7 \%$ e $33,3 \%$, respectivamente, reduziram seus efetivos de emprego, entre 2002 e 2003; felizmente, o mesmo porcentual de empresas dessas categorias conseguiu manter o número de postos de trabalho. Por outro lado, 42,9 e $57,1 \%$ das micro e pequenas empresas, respectivamente, puderam ampliar o número de empregados, entre 2002 e 2003. 
Com referência à produtividade do trabalho nas agroindústrias do arranjo produtivo, indicada pela relação entre o valor bruto da produção e o número de empregos das empresas participantes do arranjo, tem-se que as microempresas apresentaram a maior relação entre renda bruta e emprego ( $R$ \$ 30.047), seguidas pelas pequenas empresas $(\mathrm{R} \$ 26.519)$ e, por último, pelas grandes ( $\mathrm{R} \$ 14.626)$.

Outra medida de produtividade é dada pela razão entre o custo de produção e o número de pessoas empregadas na empresa. Por este indicador, a empresa mais produtiva é aquela que apresenta menor relação entre custo e emprego. A maior produtividade foi obtida pelas médias empresas ( $R \$ 2.128)$, seguidas pelas microempresas ( $R \$ 4.097)$ e pelas pequenas ( $\mathrm{R} \$ 5.468)$.

Tabela 7 - Evolução do emprego nas agroindústrias de polpa de frutas do estado do Pará, 2004

\begin{tabular}{lccc}
\hline Porte & Diminuiu & Permaneceu & Aumentou \\
\hline Micro & - & - & $42.9 \%$ \\
Pequena & $66.7 \%$ & $66.7 \%$ & $57.1 \%$ \\
Média & $33.3 \%$ & $33.3 \%$ & - \\
Total & $100.0 \%$ & $100.0 \%$ & $100.0 \%$ \\
\hline Número de empresas & $\mathbf{3}$ & $\mathbf{3}$ & $\mathbf{2 1}$ \\
\hline
\end{tabular}

Fonte: Pesquisa de campo.

Nos limites de tamanho das empresas do arranjo, as de maior escala operam com subdivisões no processo de produção e maior especialização no uso de matéria-prima e insumos, ou seja, uma combinação ajustada dos fatores de produção (trabalho, capital e capacidade de gestão). Essa prática permite ganho de eficiência e economia de custos, em razão de ganhos de experiência, isto é, a organização departamental das médias empresas, bem como a prática de rodízio e polivalência do trabalho, permitiu às médias empresas obterem maior produtividade do trabalho, que se transformou imediatamente em vantagens comparativas de custo. 
Analisando comparativamente esses resultados, obtém-se a relação entre valor gerado e custo incorrido por cada trabalhador nas agroindústrias. Em média, para cada unidade de custo com mão-de-obra geram-se R \$ 7,33 nas microempresas, $\mathrm{R} \$ 6,84$ nas médias e $\mathrm{R} \$ 4,85$ nas de pequeno porte. Observa-se que há uma margem larga para conquista dos trabalhadores, como prêmio de produtividade.

\section{Conclusões}

A principal estratégia adotada pelas empresas de polpa de frutas para atender ao objetivo de crescimento em longo prazo foi a diversificação de produto, efetivada por $67,4 \%$ das empresas entrevistadas.

Os objetivos de crescimento das empresas de polpa de frutas são, por ordem de importância, aumentar o volume de vendas $(85,2 \%)$, aumentar o tamanho da empresa $(55,6 \%)$ e maximizar o lucro da empresa $(51,9 \%)$.

Cerca de $66,7 \%$ das empresas de polpa de frutas dos pólos da mesorregião metropolitana de Belém e nordeste paraense ampliaram a capacidade produtiva em, pelo menos, $10 \%$ em 2003, em relação ao ano anterior.

Quanto ao nível de capacidade ociosa, observou-se que 46,2\% das empresas estavam operando com mais de $50 \%$, em virtude da escassez e sazonalidade de matéria-prima, falta de capital de giro, alto custo de produção e baixo poder aquisitivo da população.

Com relação à margem de lucro, $57,14 \%$ das empresas de polpa de frutas obtiveram taxa superior a 10\%, situada acima da média de 13,2\%.

A rentabilidade em curto prazo, considerando apenas os custos variáveis, obtida em 2003 , foi de $47,16 \%$ na média, sendo que $66,7 \%$ das empresas obtiveram taxa de rentabilidade superior à média.

Com relação ao market-share, cerca de $24,27 \%$ das agroindústrias mantiveram e, ou, aumentaram suas participações no mercado, simulta- 
neamente, tanto em termos de vendas como de emprego, em relação ao ano anterior.

A rentabilidade no curto prazo, considerando apenas os custos variáveis, obtida em 2003, foi de 47,2\% na média, sendo que $16,7 \%$ das empresas obtiveram taxa superior à média.

Os fatores que limitaram o desempenho das agroindústrias do arranjo produtivo de polpa de frutas, nas mesorregiões metropolitana de Belém e nordeste paraense, foram falta de capital de giro, baixa capacidade de gestão e qualificação da mão-de-obra, insuficiente capacidade de armazenamento, escassez de matéria-prima e qualidade do produto total.

Com relação aos gargalos, é necessário criar condições para acesso a capital de giro e de investimento para viabilizar a ampliação da capacidade de armazenamento do produto; implementar inovação tecnológica e de gestão e ajustar a capacidade produtiva, bem como viabilizar o acesso a novos mercados. Como o investimento em câmera frigorífica é muito pesado para as empresas individualmente, seria importante, como estratégia competitiva, fazer um grande investimento em uma câmera coletiva de armazenamento para atender ao arranjo produtivo local como um todo. A agência de Desenvolvimento da Amazônia tomou esta iniciativa.

A conclusão a que se chega, com base no balanço revelado pelos indicadores de desempenho, é que as empresas de polpa de frutas são competitivas nos mercados local, nacional e internacional, porém necessitam ajustar tamanhos, definir o mix individual e o arranjo, traçar metas coletivas e fazer funcionar uma trajetória sustentável de crescimento para $\mathrm{o}$ arranjo produtivo da fruticultura paraense como um todo. 


\section{Referências bibliográficas}

BAIN, J.S. Industrial organization. 2 ed. New York: Wiley, 1968.

BARNEY, J.B. Gaining and sustaining competitive advantage. New York: Addison-Wesley Publishing Company, 1997.

BRITTO, J. Diversificação, competências e coerência produtiva. In: KUPFER, D.; HASENCLEVER, L. (org.) Economia industrial: fundamentos teóricos e práticas no Brasil. Rio de Janeiro: Campus, 2002. p.307-343.

CABRAL, L.M.B. Introduction to industrial organization. Cambridge: The MIT Press, 2000.

ESSER, K., HILLEBRAND, W., MESSNER, D., MEYER-STANNER, J. Systemic competitiveness - new challenges to business and politics. Economics, v.59, p.62-85, 1999.

KON, A. Economia industrial. São Paulo: Nobel, 1999.

KUPFER, D., HASENCLEVER, L. (Orgs.) Economia industrial: fundamentos teóricos e práticas no Brasil. Rio de Janeiro: Campus, 2002.

MARSHALL, Alfredo. Princípios de economia. São Paulo: Abril Cultural, 1982. (livro 4)

NELSON, R.R.; WINTER, S.G. Evolutionary theorizing in economics. The Journal of Economic Perspectives, v.16, n.2, p.23-46, Spring, 2002.

NELSON, R.R.; WINTER, S.G. Toward an evolutionary theory of economic capabilities. The American Economic Review, v.63, n.2, p.440-449, May, 1973. 
PORTER, M.E. The competitive advantage of nations. New York: Free Press, 1990.

POSSAS, Sílvia. Concorrência e competitividade: notas sobre estratégia e dinâmica seletiva na economia capitalista. São Paulo: Hucitec, 1999.

SANTANA, Antônio Cordeiro de. Análise da competitividade sistêmica da indústria de madeira no Estado do Pará. Revista de Economia e Agronegócio, Viçosa-MG, v. 1, n. 2, p. 205-230, 2003.

SANTANA, Antônio Cordeiro de. Análise da estrutura e desempenho competitivo das agroindústrias de polpa de frutas do estado do Pará. Belém: UFRA; UNAMA, 2004. 49p. (Relatório de pesquisa)

TIROLE, J. The theory of industrial organization. Cambridge: MIT Press, 2001.

WILLIAMSON, O.E. The economic institutions of capitalism: firms, markets, relational contracting. New York: The Free Press, 1985.

WILLIAMSON, O.E. The mechanisms of governance. New York: Oxford University Press, 1999. 


\begin{abstract}
The objective of this paper was to determine and analyze the main competitive performance indicators of the pulp producing agro-industries of the local tropical fruits' agricluster of the Metropolitan Region of Belém and Northeast of Pará. The competitive performance was evaluated by using ex-ante and ex-post indicators of the existing industrial organization. The results showed that the firms are operating with multiple objectives and most of them are obtaining significant indicators showing an increase in the productive capacity, profit's margins, market share and employment. Finally, it is concluded that the firms of the fruits' cluster are competitive at the local, national and international markets of pulp's mix, composed by Amazon's fruits and other tropical fruits.
\end{abstract}

Keywords: Agro-industry, competitiveness, tropical fruits, Amazon. 
REVISTA DE ECONOMIA E AGRONEGÓCIO, VOL.2, $N^{\circ} 4$ 